\title{
Characteristics according to the Amount of HAp Added in Resin for Tooth Repair
}

\author{
Sungu Hwang, Jinhyuck Lim, and Suchak Ryu $\oplus^{\dagger}$ \\ Department of Nanomechatronics Engineering, Pusan National University, Busan 46241, Korea \\ (Received July 1, 2019; Revised July 22, 2019; Accepted July 29, 2019)
}

\begin{abstract}
A study was conducted to investigate the possibility of a composite material containing a composite resin as a matrix and hydroxyapatite (HAp) powder as a substitute material for tooth repair. As the content of HAp increased, hardness value (111.9 $\mathrm{HV}$ at $9 \%$ ) increased and flexural strength $(73.3 \mathrm{MPa}$ at $9 \%)$ decreased. Observation of the microstructure after immersion in a simulated body fluid (SBF) solution confirmed a dense structure due to mutual coagulation and curing. It was thought that fine HAp recrystals were formed with the lapse of time, and they were entangled to form a condensation structure and had a dense structure. In addition, since the activity was shown by the ion migration on the surface of a tooth, it was highly likely that a biocompatible bond occurred during tooth contact. Therefore, it could be used as a substitute material for tooth repair.
\end{abstract}

Key words : Hydroxyapatite, Composite, Repair, Resin, Tooth

\section{Introduction}

$\mathbf{R}$ ecently, dental materials have become a key element in all fields of dentistry, such as preservation and prosthesis, and the most commonly used are impression materials, adhesives, and restorative materials. Dental materials used as restorative materials for tooth regeneration include metal materials, ceramic materials, polymers, and composite resins. Although these materials have improved their physical properties, none of them have fully satisfied oral conditions to date. Among them, precious metal materials, such as gold and the like, are expensive and are problematic in regard to esthetics. Amalgam and nickel alloys have been developed as substitute metal materials, but they are known to be carcinogenic substances. Therefore, their biocompatibility is inadequate due to serious mercury poisoning, side effects, and environmental problems. ${ }^{1-3)}$ For an ideal dental restoration, it is desirable to replace damaged teeth with materials similar in structure and physical properties to natural teeth. Demand for metal restorative materials has also been decreasing as interest in esthetics has increased and as patients' interests have been linked to health and environmental concerns of metal restorations, such as amalgam. ${ }^{4,5)}$ Composite resins, widely used as esthetic restorative materials in dentistry, are increasingly used due to their biocompatibility, economic properties, and improved physical properties. However, there is no composite resin

Corresponding author: Suchak Ryu

E-mail : scryu@pusan.ac.kr

Tel : +82-51-510-6112 Fax : +82-51-514-2358

ORCID

https://orcid.org/0000-0002-9396-8015 that meets all of the mechanical, physical, and biocompatible properties required by the dental industry. For this reason, it is important to develop a composite material capable of improving the properties of a composite resin. One of the efforts to develop a composite resin having excellent esthetics, physical properties, and biocompatibility is to combine ceramics and polymers, and research is underway. ${ }^{3,5,6)}$ The purpose of this study was to investigate the possibility of using hydroxyapatite (HAp) as a composite material for tooth regeneration treatment. The hardness and bending strength of composite resin and HAp were measured, and they were immersed in a biofilm solution for a period of time to indirectly observe the ionic activity through the microstructure. We investigated its usability.

\section{Experimental Procedure}

\subsection{Materials}

Hydroxyapatite $\left[\mathrm{Ca}_{10}\left(\mathrm{PO}_{4}\right)_{6}(\mathrm{OH})_{2}, \mathrm{HAp}\right.$, Bone Tech. Co, Korea] powder with a purity of $98 \%$ and a particle size of 125-300 $\mu \mathrm{m}$, was used. HAp is a phosphorus calcium-based ceramic, which is chemically and crystallographically the

Table 1. Composition of B\&E Flow Resin

\begin{tabular}{lc}
\hline \multicolumn{2}{c}{$\begin{array}{l}\text { Major inorganic filler particle size: } \leq 0.7(\mu \mathrm{m}) \\
\text { Volume ratio of major inorganic filler: } 65(\%)\end{array}$} \\
\hline \multicolumn{1}{c}{ Raw material } & Quantity (\%) \\
\hline $\begin{array}{lc}\text { 2,2-bis[p-2-hydroxy-3methacryloylpropoxyl] } \\
\text { phenylpropane derivatives (Bis-GMA) }\end{array}$ & 10 \\
Triethylene glycol dimethacrylate (TEGDMA) & 10 \\
Diurethane dimethacrylate (UDMA) & 30 \\
Barium glass & 50 \\
\hline
\end{tabular}


same substance as the mineral component constituting the bones of the human body, and it has excellent biocompatibility and bone conductivity. Because of these characteristics, bone grafts in the human body can be used with implants in the medical and dental fields because they are compatible with the surrounding cells and have quick chemical bonding directly to the bone on the joints. ${ }^{2,6,7)}$ The experimental composite resin used in this study was prepared by mixing barium glass with a $0.7 \mu \mathrm{m}$ or less silane-treated resin matrix composed mainly of Bis-GMA, TEGDMA, and UDMA. B\&E flow resin was used and cured by light curing (Table 1).

\subsection{Preparation of specimens}

On the glass, frames were made with rubber tape with lengths of $3 \mathrm{~cm}$, widths of $1 \mathrm{~cm}$, and heights of $2 \mathrm{~mm}$ each. The mixture of $0.6 \mathrm{~g}$ of flow resin with $0 \mathrm{wt} \%, 1 \mathrm{wt} \%, 5 \mathrm{wt} \%$, $7 \mathrm{wt} \%$, and $9 \mathrm{wt} \%$ contents of Hap powder, respectively, were mixed and dispersed to prepare the specimens. In order to obtain the flat surface of the specimens, the glass was covered, and the bubbles were removed. The polymerization was carried out by using a D-Lux LED Curing Light (DiaDent Group International, Korea) on both sides of the specimen. Light curing $(1600 \mathrm{~mW})$ was carried out for $60 \mathrm{~s}$ at a time. For the bending strength test, the specimens, with lengths of $25 \mathrm{~mm}$, widths of $2 \mathrm{~mm}$, and heights of 2 $\mathrm{mm}$ each, were prepared according to the International Organization for Standardization (ISO 4049). ${ }^{8,9)}$

\subsection{Three-point bending strength}

The bending strength was measured by three-point bending strength measurement and conducted according to the method specified in ISO 4049 and ANSI/ADA Specification No. 27. A Universal Testing Machine (SM Tester, SME-00105T, Korea) was used, and the distance between the specimen supports was $18 \mathrm{~mm}$. The three-point bending strength $(\delta, \mathrm{MPa})$ was calculated as follows. ${ }^{9,10,11)}$

$$
\delta=3 \mathrm{~F} 1 / 2 \mathrm{bh}^{2}
$$

$\mathrm{F}(\mathrm{N})$ : Maximum load

$l(\mathrm{~mm})$ : Distance between supports $( \pm 0.01 \mathrm{~mm})$

$\mathrm{b}(\mathrm{mm})$ : Width of specimen (measured just before testing)

$\mathrm{h}(\mathrm{mm})$ : Thickness of specimen (measured just before testing)

\subsection{Vickers hardness}

For hardness value (Hv) measurements, a Vickers hardness meter with a diamond indenter was used. The average $\mathrm{HV}$ was calculated by measuring four times per specimen under the condition of $0.3 \mathrm{~kg}$ of force for $10 \mathrm{~s}$. The Vickers hardness measurement (HV) was calculated as follows: ${ }^{3,12)}$

$\mathrm{HV}=$ surface area of load $/$ pressure particle mark $=1,854$ $\times \mathrm{P} / \mathrm{d}^{2}\left(\mathrm{~kg} / \mathrm{mm}^{2}\right)$.

\subsection{Tooth immersion in HAp sol}

To observe HAp and tooth reactivity, HAp (5 wt\%) was ground and mixed with distilled water (95 wt\%) using an attrition mill (700 rpm for $3 \mathrm{~h}$ ). The tooth was immersed for 3 months in the HAp sol to observe its surface microstructure.

\subsection{Immersion in simulated body fluid}

Simulated body fluid (SBF) was prepared with a chemical composition similar to human body fluids and with the inorganic constituents of human blood plasma and similar ion concentrations. Activity of the SBF can indirectly determine the potential for bonding to a tooth. ${ }^{9,13)}$ The composite specimens were immersed in the SBF for 1 month, and the microstructures were observed.

\section{Results and Discussion}

\subsection{Measurement of bending strength}

The bending strength of the specimens is shown in Fig. 1. The results of the bending strength test showed that the specimens with 0 wt\% HAp and 1 wt\% HAp showed the highest average values (117.3 $\mathrm{MPa}$ ), and the specimens with $9 \mathrm{wt} \%$ HAp content showed the lowest average values (73.3 $\mathrm{MPa})$. In the case of the specimens with 0 wt\% HAp and $1 \mathrm{wt} \%$ HAp content, the bending strength was the same (117.3 MPa). However, as the HAp content increased from 1 wt $\%$ to 9 wt $\%$, the bending strength decreased. These

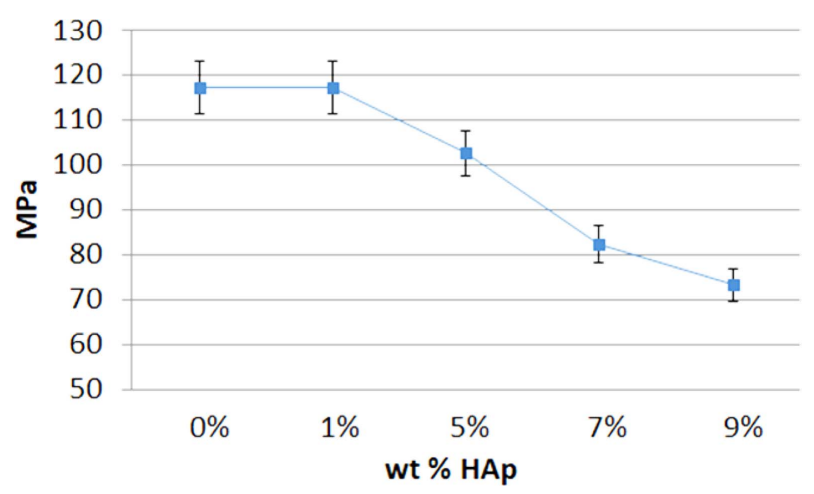

Fig. 1. The results of bending strength measurement (MPa) with the amount of hydroxyapatite (wt\% HAp).

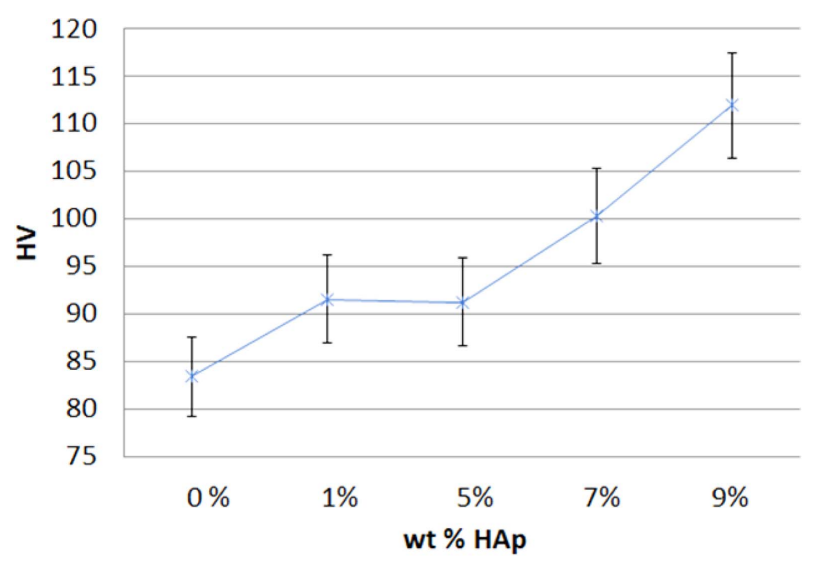

Fig. 2. The results of the Vickers hardness measurement (HV) with the amount of hydroxyapatite (wt\% HAp). 
results suggested that as the amount of HAp increased, it interfered with the resin monomer connection. In particular, the specimen with $9 \mathrm{wt} \% \mathrm{HAp}$ had a value of $73.3 \mathrm{MPa}$, which was below the ISO's recommended strength of 80 $\mathrm{MPa}$.

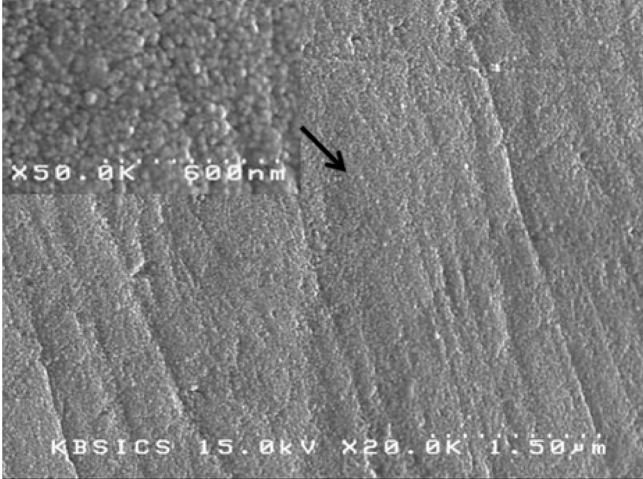

(a)

\subsection{Measurement of Vickers hardness}

The average Vickers HV of the prepared specimen is shown in Fig. 2. The results showed that the HV increased as the content of the HAp increased, compared to a standard specimen containing 0 wt\% HAp. The specimens with 0 wt\% HAp had the lowest value (83.5 HV), and the speci-

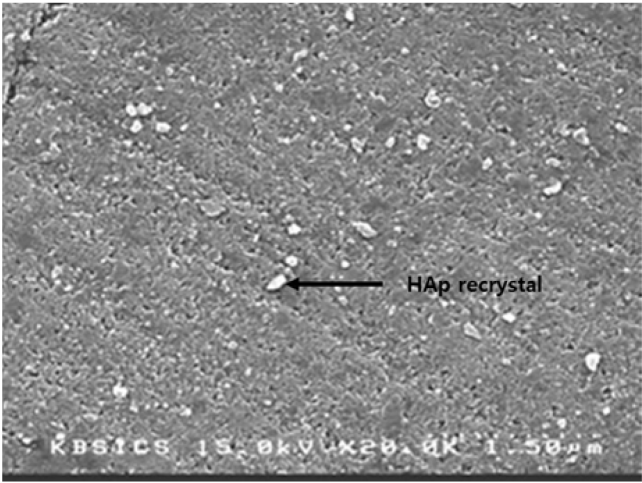

(b)

Fig. 3. Microstructures and morphologies of the tooth in HAp solution: (a) original tooth, and (b) tooth after 3 months.

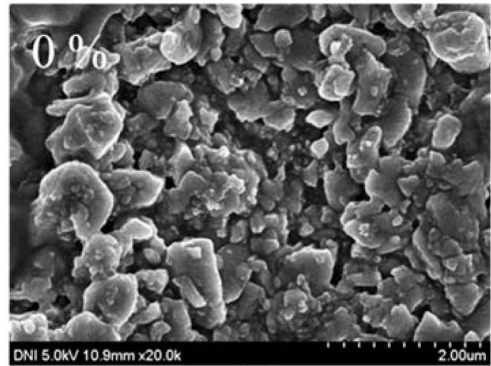

(a)

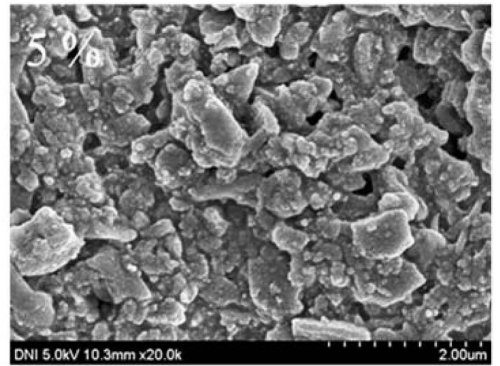

(c)

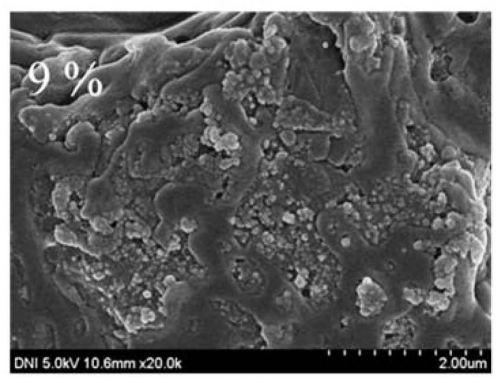

(e)

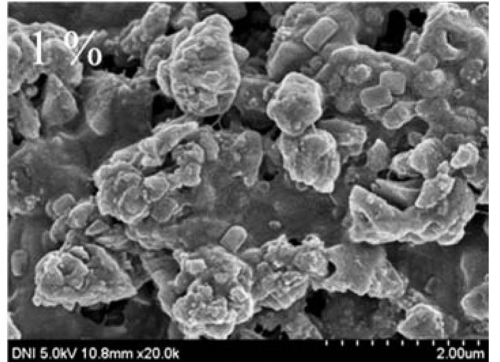

(b)

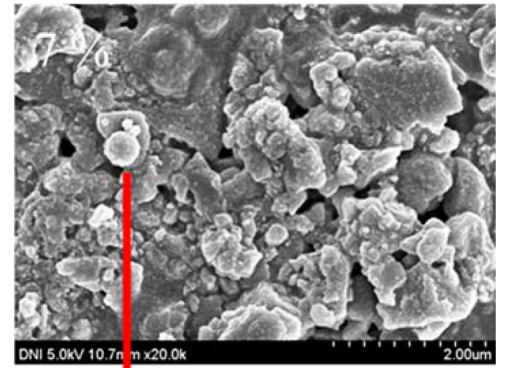

(d)

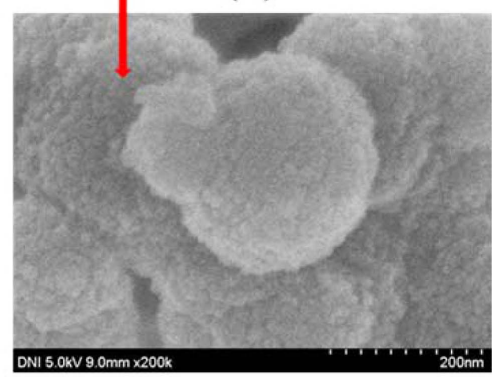

Fig. 4. Microstructures and morphologies of the specimens with different hydroxyapatite (HAp). content after 1 month in the simulated body fluid (SBF) solution: (a) $0 \mathrm{wt} \%$, (b) $1 \mathrm{wt} \%$, (c) $5 \mathrm{wt} \%$, (d) $7 \mathrm{wt} \%$, and (e) $9 \mathrm{wt} \%$ HAp powders, respectively. 
mens with 9 wt\% HAp had the highest value (111.9 HV). The HV of the specimens with a content of $1 \mathrm{wt} \%$ HAp and 5 wt\% HAp were not significantly changed, but the HV of the specimens with more than 5 wt\% HAp content significantly increased. Therefore, it was found that the hardness increased with an increasing HAp content. This result suggested that the abrasion resistance of a specimen also increased with an increasing amount of mineral mixed on the resin surface due to an increased HAp amount.

\subsection{Microstructure observation results}

The microstructure of the tooth immersed in HAp solution was observed. The surface of the tooth was porous; however, after immersion in the HAp solution, dissolved HAp filled the pores and was believed to have been deposited on the surface of the tooth by recrystallization (Fig. 3). The suggested chemical equation of this HAp recrystal reaction is as follows:

$$
\begin{aligned}
& \mathrm{Ca}_{5}\left(\mathrm{PO}_{4}\right)_{3}(\mathrm{OH})+\mathrm{nH}_{2} \mathrm{O} \leftrightarrow \\
& \quad \mathrm{xCa}^{2+}+\mathrm{y}\left(\mathrm{PO}_{4}\right)^{3-}+\mathrm{z}\left(\mathrm{HPO}_{4}\right)^{2-}+\mathrm{mH}_{2} \mathrm{O} .
\end{aligned}
$$

The microstructure and morphology were observed at 20.0 $\mathrm{k}$ magnification through a scanning electron microscope (DNI $5.0 \mathrm{kV}, 20.0 \mathrm{k}$ ) after immersing each composite specimen in the SBF solution for 1 month (Fig. 4). The microstructures of all the specimens had pores, but as the HAp content increased, the pore size and amount decreased. The microstructure of the $9 \mathrm{wt} \%$ HAp sample had the most dense structure, and it was thought that the calcium salt $\left(\mathrm{Ca}^{2+}\right)$ and the phosphate $\left(\mathrm{PO}_{4}^{3-}\right)$ ions in the SBF solution migrated. Fine crystals formed as time elapsed, and the dense structure was considered to have formed by the HAp deposition and recrystallization. In addition, the HAp of the specimen showed activity in the SBF solution. In the case of tooth recovery, the adhesive force of the polymer acted primarily on the tooth, and a mutual ion exchange occurred secondarily between the HAp and the tooth. ${ }^{2,10)}$ Therefore, the HAp composite resin was regarded as suitable to repair tooth damage.

\section{Conclusions}

In this study, Vickers hardness and strength were measured to investigate the material properties after mixing HAp powder with the composite resin as a substrate and after immersion in the SBF solution.

1. The results of the Vickers hardness test showed that hardness increased with increasing HAp contents. It was found that the addition of HAp increased the abrasion resistance of the resin composite surface.

2. As a result of the bending strength measurement, the strength decreased as the HAp content was increased over 1 wt\%. In this case, the optimum bending strength was 80 $\mathrm{MPa}$ as recommended by the ISO. Therefore, in order to use it as a substitute material for tooth regeneration treatment, we found it was appropriate to mix using a HAp content below $7 \mathrm{wt} \%$.

3. Observation of the microstructure showed that dissolved HAp was filling the pores. It was believed to have been deposited on the tooth surface by recrystallization and entangled to form a condensation structure and have a dense structure. In addition, since the activity of the calcium salt $\left(\mathrm{Ca}^{2+}\right)$ and phosphate $\left(\mathrm{PO}_{4}^{3-}\right)$ ions in the $\mathrm{SBF}$ solution was exhibited at the surface of the tooth, it was considered that the possibility of biobonding is high during tooth contact.

These results suggested that it is possible to use HAp composite resin as a substitute material for tooth regeneration treatment.

\section{Acknowledgments}

This work was supported by a 2-Year Research Grant of Pusan National University.

\section{REFERENCES}

1. D.-S. Seo, H. Kim, and J. K. Lee, "Surface Dissolution of Hydroxyapatite Biomaterials with Ca/P Ratio," J. Korean Ceram. Soc., 41 [1] 45-50 (2004).

2. S. C. Ryu, "Study on the Tooth Recovery Material Using with Hydroxyapatite," J. Korean Ceram. Soc., 42 [10] 660-64 (2005).

3. Y.-J. Jung, Y.-J. Kim, J.-W. Kim, S.-H. Lee, C.-C. Kim, S.H. Hahn, and K.-T. Jang, "Effects of Nanofiller Content on the Microhardness of Experimental Microhybrid Resin Composites," J. Korean Acad. Pediatr. Dent., 32 [1] 7-12 (2005).

4. D. G. Seo and B. D. Roh, "The Comparison of Relative Reliability on Biaxial and Three Point Flexural Strength Testing Methods of Light Curing Composite Resin," $J$ Korean Acad Conserv Dent., 31 [1] 58-65 (2006).

5. S.-W. Ku, J.-H. Park, and Y.-M. Ko, "Mechanical Properties of Ceramic/Polymer Blocks for CAD/CAM Dental Restoration," Korean Soc. Dent. Mater., 44 [2] 107-17 (2017).

6. J.-H. Kim, Y.g-U. Sim, T.-Y. Yang, S.-Y. Yoon, and H.-C. Park, "Biomimetio Apatite Preoipitated on the Surface of Titanium Powder," J. Korean Ceram. Soc., 47 [2] 127-31 (2010).

7. H.-H. Jin, D.-H. Kim, T.-W. Kim, H.-C. Park, and S.-Y. Yoon, "Degradation Behavior of Hydroxyapatite with Different Crystallinity in Simulated Body Fluid Solution," Korean J. Mater. Res., 21 [6] 347-51 (2011).

8. Y.-W. Im, S.-S. Hwang, S.-H. Kim, and H.-H. Lee, "Effects of Specimens Dimension on the Flexural Roperties and Testing Reliability of Dental Composite Resin," Korean J. Dent. Mater., 44 [3] 273-80 (2017).

9. Y.-W. Im and S.-S. Hwang, "Evaluation of Flexural Properties of Indirect Gum-Shade Composite Resin for Esthetic Improvement," J. Dent. Hyg. Sci., 15 [4] 407-12 (2015).

10. J.-I. Yoo, S.-Y. Kim, B. Batbayar, J.-W. Kim, S.-H. Park, and K.-M. Cho, "Comparison of Flex- ural Strength and Modulus of Elasticity in Several Resinous Teeth Splinting 
Materials,” J. Dent. Rehabil Appl. Sci., 32 [3] 169-75 (2016)

11. Y. W. Im, S. S. Hwang, and H. H. Lee, "Evaluation of Flexural Properties by 3-point and 4-point Flexural Test Method of Dental Composite Resins," Korean. J. Dent. Mater., 42, 65-66 (2015).

12. K. H. Kim, "Nickel Amalgamation by Electro-Deposition
Process Using Mercury Cathode and its Properties," J. Korean Inst. Surf. Eng., 38 [5] 198-201 (2005).

13. Y. W. Im, B. S. Song, and H. H. Lee, "Correlation of the Mechanical Properties of Dental Composite Resin with Filler Content," Korean. J. Dent. Mater., 40(spec), 22-24 (2013). 